\section{耍 Heighten Science \\ P U B L I C I T I O N S Corporation ISSN 2639-6629}

\title{
Cardiovascular risk reduction: Past, present and future in Mexico
}

Martin Rosas-Peralta1, Gabriela Borrayo-Sánchez ${ }^{2 *}$, Erick Ramírez-Arias ${ }^{3}$, Gladys $M$ Jiménez-Genchi ${ }^{4}$, Martha Alicia Hernández-González ${ }^{5}$, Rafael Barraza-Félix ${ }^{6}$, Lidia Evangelina Betacourt-Hernández ${ }^{7}$, Rocio Camacho-Casillas ${ }^{8}$, Rodolfo Parra-Michel ${ }^{9}$, Héctor David Martínez Chapa $^{10}$ and José de Jesús Arriaga-Dávila ${ }^{11}$

\author{
"Head of Medical Area, Commissioned of "A todo Corazón-Código Infarto" program. National \\ Medical Center, XXI century, IMSS, México \\ ${ }^{2}$ Commissioned General Coordinator of "A todo Corazón-Codigo Infarto" program, National \\ Medical Center, XXI century, IMSS, México \\ ${ }^{3} \mathrm{Head}$ of Emergency Room. UMAE Cardiology Hospital, National Medical Center, XXI Century, \\ IMSS, México \\ ${ }^{4}$ Ex-Coordinator, Education and Research, UMF 65, IMSS, México \\ ${ }^{5} \mathrm{Head}$ of Research and Educational Division UMAE No. 1 HE Centro Médico Nacional del Bajío, \\ Guanajuato, IMSS, México \\ 'UMAE HE Centro Medico la Raza, IMSS, México \\ 'UMAE, HE No. 14 Veracruz, IMSS, México \\ ${ }^{8} \mathrm{UMAE}, \mathrm{HE}$ Torreón Coahuila, IMSS México \\ ${ }^{9} \mathrm{Head}$ of Coronary Care Unit, UMAE, HE Centro Médico de Occidente, Guadalajara Jal. IMSS México \\ ${ }^{10} \mathrm{Head}$, Medical Attention Unit, IMSS-México \\ ${ }^{11}$ Director of Medical Benefits, IMSS-México
}

\begin{abstract}
*Address for Correspondence: Gabriela Borrayo-Sánchez, Head and Commissioned of "A Todo Corazón-Código Infarto" Program National Medical Center, XXI Century. IMSSMéxico, Tel: (52) 5526545801; Email: gborrayos@yahoo.com.mx

Submitted: 07 June 2018

Approved: 16 July 2018

Published: 17 July 2018

Copyright: @ 2018 Sánchez GB , et al. This is an open access article distributed under the Creative Commons Attribution License, which permits unrestricted use, distribution, and reproduction in any medium, provided the original work is properly cited
\end{abstract}

Keywords: Cardiovascular risk; Hypertension Diabetes; Dyslipidemia; Obesity; Mexico

\section{Summary}

Atherosclerotic cardiovascular disease (ASCVD) is globally defined as coronary heart disease, cerebrovascular disease, or peripheral arterial disease presumed to be of atherosclerotic origin and it is the leading cause of morbidity and mortality for individuals with or without diabetes and is the largest contributor to the direct and indirect catastrophic costs of cardiovascular disorder. Very common conditions coexisting into the cardiovascular risk (e.g., obesity, hypertension, diabetes and dyslipidemia) are clear risk factors for ASCVD, and diabetes itself confers independent risk. Numerous studies have shown the efficacy of controlling individual cardiovascular risk factors in preventing or slowing ASCVD in people with these disorders. In other words it is not enough control one risk factor. We need to develop novel strategies to detect and control all of them at the same time. Thus, large benefits are seen when multiple cardiovascular risk factors are addressed simultaneously. Under the current paradigm of aggressive risk factor modification in patients with cardiovascular risk, there is evidence that measures of 10-year coronary heart disease (CHD) risk among U.S. adults with cardiovascular risk have improved significantly over the past decade and that ASCVD morbidity and mortality have decreased. In Mexico the Mexican Institute of Social Security is implementing new strategies of primary and secondary prevention in order to confront this pandemic.

In this review, we analyze the state of the art to approach at the same time the different cardiovascular risk factors, in an integral form because of this is the real worldwide challenge of health.

\section{Introduction}

The increasing burden of cardiovascular disease (CVD), along with rising costs, is driving a renewed focus on cardiovascular disease risk reduction. More and more, prevention and population health are in the spotlight in scientific meetings and journals.

How to cite this article: Peralta MR, Sánchez GB, Arias ER, Genchi GMJ, González MAH, et al. Cardiovascular risk reduction: Past, present and future in Mexico. Ann Clin Hypertens. 2018; 2: 038-047. https://doi.org/10.29328/journal.ach.1001010 
This high-value, high-return approach to addressing cardiovascular disease has the potential to prevent at least 200,000 deaths from heart disease and stroke each year in the United States [1]. Depending on the geographic region, age- adjusted preventable cardiovascular death rates range from 18 to 182 per 100,000 people [2]. The CVD in Mexico still as the number one cause of death and only recently the mortality has improved because of implementation of code infarction. Experts agree that health care providers need to focus on preventive and lifestyle aspects of cardiovascular care to promote individual and population health.

In other words, it is not possible to continue considering the factors of cardiovascular risk in isolation form, the concatenation of these factors takes place in the real world. As you can see in the Table 1 we illustrate this phenomenon. We used Cross tables previous published [3] by our group to illustrate the impact of different conditions on the prevalence of a cardiovascular risk factors in order to keep always this concept. Thus the prevalence of hypercholesterolemia in this study was depending on age, but also by sex and body mass index. Therefore the occurrence of cardiovascular risk factors is depending on multiple situations and we need to keep in mind this concept when we talk about prevalence of cardiovascular risk factors [3].

Cardiovascular disease risk reduction revolves around the major risk factors, including hypertension, hyperlipidemia, obesity and diabetes. Although some risk factors, such as age and hereditary factors cannot be modified, lifestyle modification is the key to preventing cardiovascular disease. Risk assessment analyses have shown that lifestyle-related risk factors are the major causes of death and disability in the U.S. and the world [4]. Heart healthy diets, regular physical activity, smoking cessation and maintaining a healthy weight comprise the foundation for cardiovascular disease risk reduction. We need to remember that atherosclerosis has essentially 7 factors to be considered. Two are mechanics (Hypertension and obesity), two are chemicals (hyperglycemia and cholesterol) and three of behavioral origin (Bad food, excessive alcohol and smoking).

\section{Hypertension}

Hypertension is the number one cardiovascular risk factor and the world's greatest risk factor for death and disability, according to the World Health Organization. Approximately 85.7 million U.S. adults 20 years of age and older have hypertension, with the highest rates in African Americans [1,2]. From 2003 to 2013, the number of deaths attributable to hypertension increased by 34.7 percent. People with hypertension are three-times more likely to die from heart disease and four-times more likely to die from stroke [3,4]. In Mexico there are 22.3 millions of hypertensive adult population. The prevalence is directly related by age, sex, diabetes and BMI $[3,5]$.

According to the National Health and Nutrition Examination Survey (NHANES), from 2009 to 2012, hypertension was controlled among 54.1 percent of people with hypertension, 76.5 percent were currently treated, 82.7 percent knew they had

Table 1: Prevalence of hypercholesterolemia (>200 mgrs) according with age, gender and body mass index. AGE GROUPS (years).

\begin{tabular}{|c|c|c|c|c|c|c|c|c|c|c|}
\hline & & \multicolumn{3}{|c|}{$20-34$} & \multicolumn{3}{c|}{$35-54$} & & $55-69$ & \\
\hline BMI $(\mathrm{kg} / \mathrm{m} 2)$ & $<25$ & $20.70 \%$ & $19.10 \%$ & $1.60 \%$ & $42.10 \%$ & $39.90 \%$ & $2.20 \%$ & $41.50 \%$ & $52.70 \%$ & $-11.20 \%$ \\
\hline & $25-29.9$ & $34.20 \%$ & $28.80 \%$ & $5.40 \%$ & $50.00 \%$ & $47.50 \%$ & $2.50 \%$ & $45.60 \%$ & $60.90 \%$ & $-15.30 \%$ \\
\hline & 30 or more & $39-90 \%$ & $32.70 \%$ & $7.20 \%$ & $50.00 \%$ & $47.40 \%$ & $2.60 \%$ & $45.60 \%$ & $57.60 \%$ & $-12.00 \%$ \\
\hline & & $31.30 \%$ & $25.60 \%$ & $5.70 \%$ & $48.30 \%$ & $45.80 \%$ & $2.50 \%$ & $44.60 \%$ & $57.90 \%$ & $-13.30 \%$ \\
\hline Subtotal & & & $28.10 \%$ & & & $46.80 \%$ & & & $55.20 \%$ & \\
\hline Total & $\mathrm{n}$ & 16,020 & & 16,732 & 24,346 & & 35,208 & 9,625 & & 6,549 \\
\hline & $\mathrm{N}$ & & 34,333 & & & 59,554 & & & 26,118 & \\
\hline
\end{tabular}

BMI, Body Mass Index, data from reference 3. 
hypertension and 17.3 percent were undiagnosed [4]. The Centers for Disease Control and Prevention (CDC) recommend a three-pronged approach to blood pressure control. Health care systems should use electronic health records (EHRs) and patient registries to identify and control hypertension. Health care providers should use a team- based approach, check blood pressure at every visit and simplify treatment (once-a-day doses; fewer pills). Blood pressure control improves when patients comply with medications, measure their blood pressure, eat a healthy low sodium diet, increase physical activity, maintain a healthy weight, limit alcohol use and avoid smoking.

In Mexico [5], the percentage of patients who ignore be hypertensive is around $50 \%$, and only half of those who know to be hypertensive are controlled, Figure 1.

The new clinical practice guideline for high blood pressure from the ACC and American Heart Association [6] recommends 10-year risk assessment for atherosclerotic cardiovascular disease (ASCVD) to guide treatment, along with strategies to improve hypertension treatment and control, proper blood pressure measurement and structured, team-based approaches to care [5]. The threshold for treatment is determined by the ASCVD risk assessment. For the vast majority of patients with stage 2 hypertension, the initial recommended action is one or more nonpharmacological interventions. Table 2 defines the categories of blood pressure in adults [6].

Impact of new ACC/AHA criteria [6] for diagnosis of Hypertension in countries like Mexico

In Mexico for example at the middle of 2017 exists around 128 million people, 65\% of them ( 76 million) corresponds to population aged over 20 years old. Prehypertension or also called borderline blood pressure was considered in previous JNC-8 report and its prevalence was informed around $25-30 \%$ in the adult population. In Mexico, the prevalence of pre hypertension was informed in 2015 to be $37.5 \%$ (95\%confidence interval (CI): $36.0-39.0$ ): $46.7 \%$ were men (95\% CI: $44.1-49.4$ ) and 33.2\% (95\% CI: 31.5 5.0) were women [5]. This is a very relevant national health situation because of $37 \%$ of prehypertension in Mexico represents around 30.9 million adult population. In addition with a prevalence estimated in $30 \%$ around 22.8 million would be within the diagnosis of hypertension with criteria of $140 / 90 \mathrm{mmHg}$, but with the new criteria of the AHA, as we mentioned before, the population with hypertension is at least twice ( $\sim 50$ million).

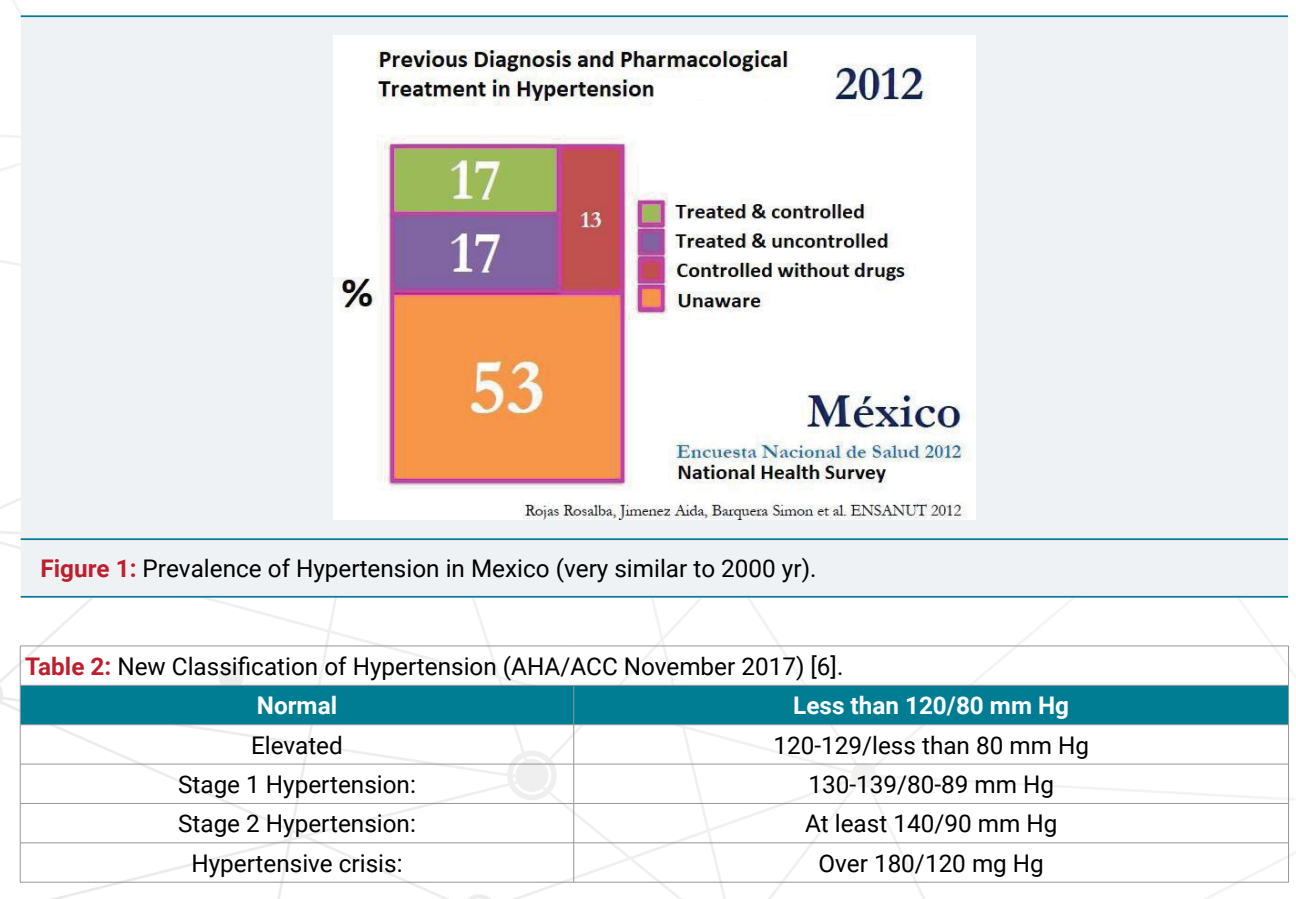


This is a real epidemiological alert that will require new strategies to confront it. Therefore, In other words, we need programs to prevention and treatment that should be established to around 53 million of adults in Mexico. It reinforce epidemiological alert of an old problem with new diagnostic-therapeutic challenges. Fortunately in the Mexican Institute of Social Security that cover $3 / 4$ parts of the total Mexican population, there are several novel strategies directed to confront this pandemic with primary and secondary prevention.

Nevertheless, the problem does not end with the new number of patients with a diagnosis of hypertension. It must take into account that the rate of patients detected, treated and controlled with the previous breakpoint of $140 / 90 \mathrm{mmHg}$ was low and not enough, therefore with the new cut-off point of $130 / 80 \mathrm{mmHg}$, the percentage of patients with hypertension controlled is reduced even more. While the focus of ACC/AHA [6] seeks to address with greater emphasis preventive and non-pharmacological actions to treat hypertension implications real in countries like Mexico represent one major health challenge it publishes. The need to establish a position is clear and necessary. Nonetheless, should always have it in mind that the hypertension is not an isolated entity, it is often as we mentioned concatenated with other risk factors, and there is a real interaction of facilitation, i.e. a hypertensive patient is more prone to be diabetic and the same thing happens to the reverse. The same phenomenon applies with obesity and Dyslipidemia.

\section{Dyslipidemia}

High cholesterol, present in nearly one in three U.S. adults, is a major risk factor for cardiovascular disease. In 2011 to 2012, the targets for total cholesterol were met in 75.7 percent of children $(<170 \mathrm{mg} / \mathrm{dL})$ and 46.6 percent of adults $(<200 \mathrm{mg} / \mathrm{dL})$. Declining cholesterol levels in recent years are attributable to greater use of cholesterollowering drugs rather than dietary changes [1]. In Mexico the prevalence and low rate of control still to be considered as a great challenge [3]. In countries like United States these gains are primarily due to the use of statins. Recently, PCSK9 inhibitors produced striking reductions in LDL-C that, in the long term, reduced the incidence of subsequent coronary events in people with existing coronary disease and alirocumab reduced mortality in ODYSSEY Outcomes [7]. Still, adding lifestyle components that incorporate dietary changes and physical activity, even when cholesterol is controlled with medications, promotes lifestyle changes that also contribute to long term-health, longevity and well-being. The Million Hearts Program recommends limiting saturated and trans fats and increasing fiber in the diet, getting regular physical activity, maintaining a healthy weight and smoking cessation [6]. Again, Hypercholesterolemia is not an isolated disease, we need to keep in mind the global context of the subject to analyse the real probability of occurrence [3] Table 3.

\section{Diabetes}

One in 10 U.S. adults has diabetes and 90 to 95 percent of cases are type 2 diabetes. Type 2 diabetes disproportionately affects minorities and is increasingly common among children and adolescents [8]. Diabetes is associated with a two- to threefold increased risk of cardiovascular disease, which is more likely to be the cause of hospitalization in patients with diabetes than diabetes-related causes. Experts recommend prevention of cardiovascular events as the goal of diabetes treatment [8].

Two new classes of drugs-sodium-glucose co-transporter 2 (SGLT-2) inhibitors and glucagon-like peptide-1 (GLP-1) receptor agonists-have been shown to reduce cardiovascular events, beyond their glucose-lowering benefit. The American Diabetes Association recommends lifestyle management in addition to medications for the management of diabetes and cardiovascular risk factors, including nutrition therapy, physical activity and smoking cessation [8].

Regardless of diagnosis and control of diabetes, other risk factors must be addressed comprehensively. Thus, will not be the same a diabetic with obesity, Dyslipidemia, and hypertension, that a diabetic with hypertension stage 1 (Table 4). 
Table 3: Prevalence of Hipercholesterolemia (>200 mg/dl) by age, gender and body mass index ; Impact of Hypertension.

\begin{tabular}{|c|c|c|c|c|c|c|c|c|c|c|c|}
\hline \multicolumn{12}{|c|}{ Prevalence of Hipercholesterolemia Conjuntive Consolidation method. N=120,005 } \\
\hline \multicolumn{4}{|c|}{ Population without Hypertension (69.8\%) } & \multicolumn{8}{|c|}{ Age Groups (yr) } \\
\hline & & & \multicolumn{3}{|c|}{ 20-34 } & \multicolumn{3}{|c|}{ 35-54 } & \multicolumn{3}{|c|}{$55-69$} \\
\hline \multicolumn{3}{|c|}{$\mathrm{BMI}(\mathrm{kg} / \mathrm{m} 2)$} & Hombre & Mujer & Dif \% & Hombre & Mujer & Dif \% & Hombre & Mujer & Dif \% \\
\hline & \multicolumn{2}{|l|}{$<25$} & $19.80 \%$ & $18.80 \%$ & $1.00 \%$ & $39.60 \%$ & $38.00 \%$ & $1.60 \%$ & $36.70 \%$ & $47.40 \%$ & $-10.70 \%$ \\
\hline & \multicolumn{2}{|l|}{$25-29.9$} & $33.40 \%$ & $28.20 \%$ & $5.20 \%$ & $48.60 \%$ & $45.50 \%$ & $3.10 \%$ & $41.70 \%$ & $56.80 \%$ & $-15.10 \%$ \\
\hline & \multicolumn{2}{|l|}{30 o mas } & $38.00 \%$ & $31.30 \%$ & $6.70 \%$ & $47.90 \%$ & $44.80 \%$ & $3.10 \%$ & $44.50 \%$ & $55.70 \%$ & $-11.20 \%$ \\
\hline & & & $29.80 \%$ & $24.60 \%$ & $5.20 \%$ & $46.50 \%$ & $43.30 \%$ & $3.20 \%$ & $40.80 \%$ & $53.80 \%$ & $-13.00 \%$ \\
\hline \multicolumn{3}{|l|}{ Subtotal } & & $27.20 \%$ & & & $44.90 \%$ & & & $47.30 \%$ & \\
\hline \multirow[t]{2}{*}{ Total } & & $\mathrm{n}$ & 13,502 & & 14,895 & 17,270 & & 25,229 & 4,886 & & 7,965 \\
\hline & & $\mathrm{N}$ & & 28,398 & & & 42,499 & & & 12,851 & \\
\hline \multicolumn{4}{|c|}{ Hipertensive Population (30.2\%) } & \multicolumn{8}{|c|}{ Age Groups (yr) } \\
\hline & & & \multicolumn{3}{|c|}{$20-34$} & \multicolumn{3}{|c|}{$35-54$} & \multicolumn{3}{|c|}{$55-69$} \\
\hline \multicolumn{3}{|c|}{ BMI (kg/m2) } & Hombre & Mujer & Dif \% & Hombre & Mujer & Dif \% & Hombre & Mujer & Dif \% \\
\hline & \multicolumn{2}{|l|}{$<25$} & $29.50 \%$ & $23.20 \%$ & $6.30 \%$ & $53.40 \%$ & $50.20 \%$ & $3.20 \%$ & $49.50 \%$ & $59.60 \%$ & $-10.10 \%$ \\
\hline & \multicolumn{2}{|l|}{$25-29.9$} & $39.40 \%$ & $34.30 \%$ & $5.10 \%$ & $53.80 \%$ & $53.50 \%$ & $0.30 \%$ & $49.60 \%$ & $64.30 \%$ & $-14.70 \%$ \\
\hline & \multicolumn{2}{|l|}{30 o mas } & $44.50 \%$ & $38.10 \%$ & $6.40 \%$ & $51.70 \%$ & $51.40 \%$ & $0.30 \%$ & $46.30 \%$ & $58.60 \%$ & $-12.30 \%$ \\
\hline & & & $39.70 \%$ & $33.40 \%$ & $6.30 \%$ & $52.97 \%$ & $51.70 \%$ & $1.27 \%$ & $48.47 \%$ & $60.83 \%$ & $-12.37 \%$ \\
\hline Subtotal & & & & $36.55 \%$ & & & $52.33 \%$ & & & $54.65 \%$ & \\
\hline \multirow[t]{2}{*}{ Total } & & $\mathrm{n}$ & 2,715 & & 1,837 & 7,076 & & 9,979 & 4,739 & & 10,109 \\
\hline & & $N$ & & 4,552 & & & 17,055 & & & 14,848 & \\
\hline
\end{tabular}

Data from reference [3].

Table 4: Randomized controlled trials of intensive versus standard hypertension treatment strategies.

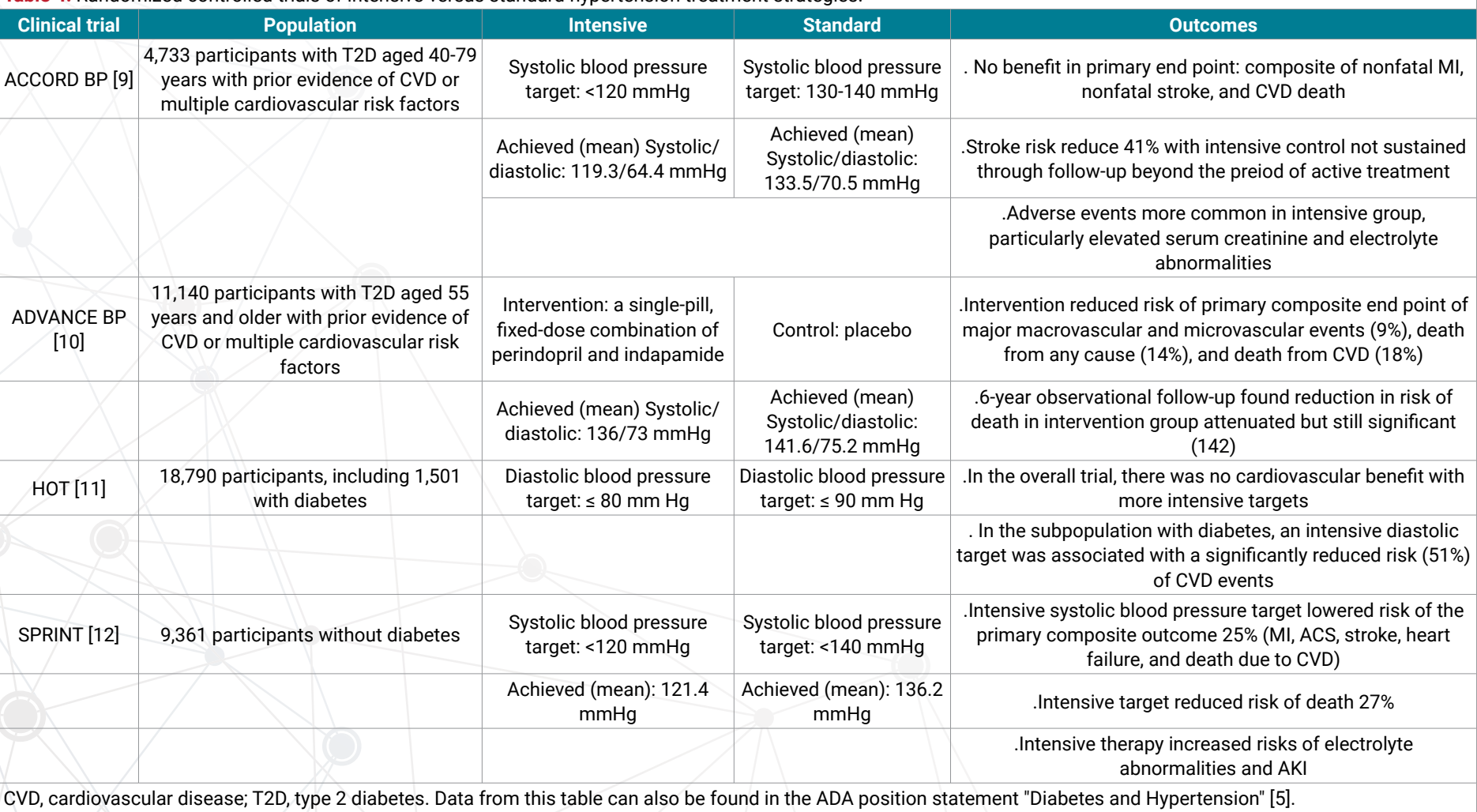

\section{Obesity [13]}

Obesity and overweight are the most common chronic condition and its prevalence is increasing. In Mexico more than 70\% of adults are overweight or obese (BMI > 25) in children this entity is on the vertiginous rise. This condition is associated with an increase in cardiovascular risk, diabetes mellitus, arterial hypertension, vascular event cerebral, osteoarthritis and certain types of cancer. It is estimated that this condition costs exceed the 50 billion of Mexican pesos. This is another big challenge to the social development of the nation. 
In the recent national survey of Mexico (2016) we found among school-age children, 17.9\% (95\%CI: 15.2-21.1) were overweight and 15.3\% (95\%CI: 12.5-18.6) Obese. This represented a total of $33.2 \%$ ( 5 million 253 thousand) overweight schoolchildren versus $34.4 \%$ in 2012. Prevalence predominated among 10-11-y-olds and was 6 percentage points (PPs) higher in urban than in rural areas. Among adolescents, $22.4 \%$ (95\%CI: 19.5, 25.6) and 13.9\% (95\%CI: 11.4, 16.8) presented overweight and Obesity, respectively. Compared to 2012, the overall overweight+ obesity in adolescents declined just only $1 \%$ (previous 35\%) [14].

The principal mechanisms by which obesity cause cardio-metabolic disorders are showed in figure 2 .

The loss of moderate weight, defined as a reduction of 5 to $10 \%$ in the baseline weight, is associated with clinically significant improvements in metabolic risk factors related to obesity and disorders coexistentes. 9,38,39 a 5\% weight loss improves the function of pancreatic $\beta$ cells and the sensitivity of liver and skeletal muscle insulin; A relative weight loss wholesale leads to improvements graduated in key disorders tissue adiposo.40, 41 A year, patients had a weight loss average of 8.6 per cent from the baseline, which was accompanied by significant reductions in systolic blood pressure and diastolic (6.8 and $3.0 \mathrm{~mm} \mathrm{Hg}$, respectively) and triglyceride levels (30.3 mg per deciliter [0.34 mmol per liter]) and (from $0.64 \%$ ) glycosylated hemoglobin. A response graduated for these sensitive measures the weight, with further loss of weight accompanied by greater improvements were observed [13].

Moderate weight loss can result in the prevention of disease in people at high risk. Overweight or obesity and impaired glucose tolerance patients who received an intensive lifestyle intervention in the Diabetes prevention program had a weight loss average of $5.6 \mathrm{~kg}$ at 2.8 years and a relative reduction of $58 \%$ of risk to developed $[14,15]$.

Losses average of 16 to $32 \%$ of the baseline weight produced by weight loss surgery in patients with severe obesity can lead to remission of the disease, including remission of diabetes type 2 in patients undergoing surgery, in particular the gastric bypass, have also shown significant reductions in mortality from all causes in observational studies of patients treated surgically $[16,17]$.

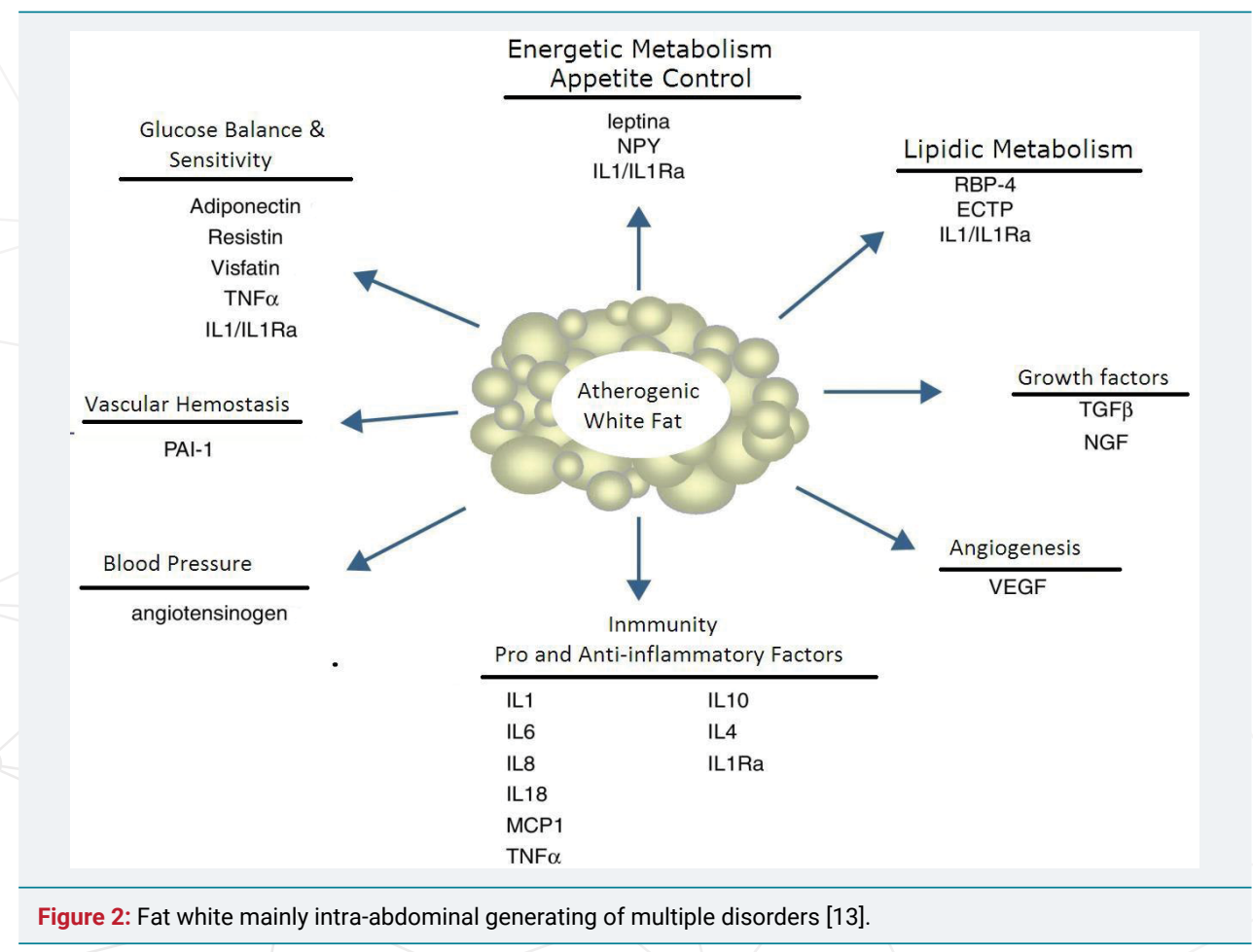


Although weight loss is an effective therapeutic measure of broad action, not all risk factors and chronic disease States respond equally bien. 38,39-42 severe obstructive sleep apnea, for example, improves but rarely forwards fully in response to treatments for weight loss, including Bariatric Surgery [17].

On the other hand, the moderate weight loss beneficial clinical effects achieved with intensive intervention in the style did not reduce the morbidity and mortality associated with cardiovascular disease after 9.6 years in the study [18]. Well established medical therapies should be used with weight loss to achieve good control of coexisting conditions linked to obesity. Similarly, the symptoms of some psychiatric disorders can improve with weight loss, but complementary psychiatric care is critical, particularly in people with moderate or severe disorders. For example, shown that the complementary care is invaluable for improving mental health and eating behaviours, such as the binge eating syndrome.

\section{Nutritional aspects}

Poor diet is the leading risk factor for death and disability in the U.S. and was responsible for 678,000 deaths from all causes in 2010. Insufficient intake of fruits, vegetables, nuts and seeds, whole grains, and seafood, as well as excess sodium intake are considered major contributors. In fact, the best improvements in heart health through risk factor reduction have been seen with a predominantly plant-based diet that emphasizes green, leafy vegetables, whole grains, legumes and fruit. Limitation of dietary cholesterol is also recommended.

Numerous observational studies have demonstrated the benefit of a Mediterranean style diet on cardiovascular risk reduction. The PREDIMED trial showed that a Mediterranean diet with increased mixed nuts or substitution of extra-virgin oil for regular olive oil reduced cardiovascular events by 30 percent [19]. While this is exemplary, it represents a 70 percent persistence of events, with residual risk reduction opportunities through further refinement of diet [19].

\section{Cardiovascular risk evaluation in obesity}

One of the aspects most relevant consequences of obesity is its impact as a cardiovascular risk factor (Figure 3).

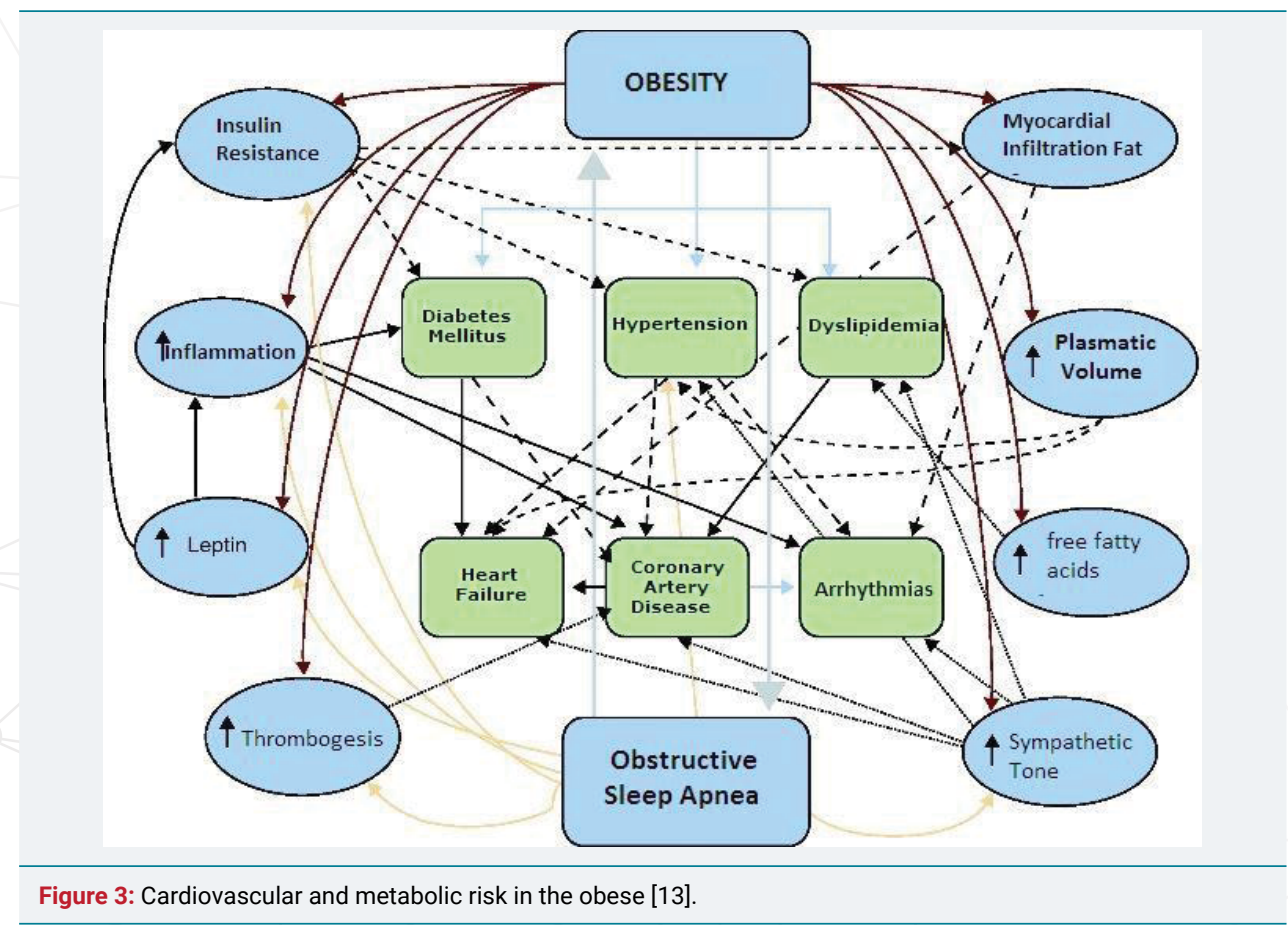


The recognition of the Adipocyte as an endocrine cell activates and not only had a simple repository of lipid revolutionized the understanding of the underlying mechanisms that promote and develop cardiovascular risk factors. Thus, the obese patient generates insulin resistance, favors high blood pressure and diabetes, Endothelial dysfunction, diabetes, thrombogenic disorder and disorders in lipid metabolism, stimulates abnormal growth of extracellular matrix, metalloproteins and promotes infiltration of lipids in tissue, skeletal muscle, liver and even promotes hypertrophy, myocardial and flattering diastolic dysfunction of cardiac arrhythmias.

Thus, the adipose tissue synthesized and secret molecules biologically active that they affect cardiovascular risk factors. These chemical messengers including adiponectin, resistin, leptin, Inhibitor of the activator of plasminogen-1, Interleukin-6 and tumoral necrosis factor. In individuals with overweight and obesity, weight loss may improve sensitivity to insulin, leading to the reduction of risk factors for cardiovascular diseases and, accordingly, the potential for cardiovascular events.

\section{Smoking}

Smoking continues to be a harmful behavior of high cardiovascular risk. This habit power the risk of hypertension and atherosclerosis. Although many efforts have been made in its detection and treatment must be in the full context of warning of chronic diseases.

\section{Future in countries like mexico a preventive model [20]}

Lifestyle interventions designed to change eating behaviors and physical activity are the first choice for the weight management, given its low cost and minimum risk of complications. The goal for patients who have overweight or obesity is to improve the health and quality of life by achieving and maintaining moderate weight loss. Extensive research led to the current recommendations that patients receive advice behavior of high intensity, with 14 or more trips in 6 months. A comprehensive program, carried out by a trained interventionist, resulting in a loss of average weight of 5 to $8 \% 39$ and approximately 60 to $65 \%$ of patients lost $5 \%$ or more of the initial weight (weight loss 1 year high in lifestyle interventions intensity or drug therapy combined with counseling of low to moderate intensity lifestyle).

\section{Adult educational program. Mexican Institute of Social Security (IMSS) 2018}

Education for patients with chronic no communicable disease is crucial for Health. Behavioral therapy, core of the lifestyle intervention, provides the patients techniques to adopt dietary recommendations and activity. At the IMSS these recommendations include the regular recording of food intake, physical activity and weight. This task can be facilitated by smart phones applications, activity meters and scales with cellular connection. Patients review their progress approximately once a week with a trained interventionist providing stimulus and targets and troubleshooting instructions.

Fifty-fifty program was born from the initiative of the Foundation SHE, promoted by Dr. Valentín Fuster [21], in order to improve health comprehensively in adults by modifying their health habits. The scientific study, which shows that the program has a positive impact on cardiovascular health, has counted with the support of the Spanish Agency of consumption, food safety and nutrition (AECOSAN) of the Ministry of health, social services and equality, in the framework of the NAOS strategy and the Observatory of nutrition and obesity study. In the IMSS this program started with promising results.

\section{Education in children of mexico}

SI Program of Dr. Valentín Fuster [22] consisted of education to pre-school children of 3 to 5 years in Spain, achieving major changes in habits and customs in favor of nutrition and body weight. The IMSS is preparing in collaboration with Spain 
a similar program in Mexico. The program aims to improve the overall health in adults helping them to correct their health habits and self-manage the major risk factors for cardiovascular disease: not healthy eating, Overweight/obesity, physical inactivity, smoking and high blood pressure.

\section{Barriers to treatment}

Only a small fraction of patients for whom these three kinds of treatments are actually receives them. Barriers to care include slow recognition by the health care providers that obesity requires a long-term management, inadequate training of physicians in nutrition and obesity, a refund limited the full range of the lack of effective and affordable lifestyle programs and treatments.

While Bariatric Surgery is a treatment option for improving health of level (i.e., with improvements based on data from randomized trials or meta-analyses). 39 the hope is that you a growing national, multidisciplinary network of medical professionals that they have been trained and certified in the treatment of obesity surpass some of these impediments to effective patient care.

\section{Primary and secondary prevention (Role of Fixed-Dose Combination Drug, CV polypill)}

Some additional strategies to education have enabled better control of cardiovascular risk in a comprehensive manner. Recently it has been shown that the use of drugs that individually have been proven its effectiveness and safety for some cardiovascular risk factor control can be combined into a single presentation. This improves the adhesion and therefore the control of the factors of risk in a comprehensive manner. Mexico is this testing in postinfarction patients (study of real-world) and high-risk patients (diabetics and hypertensive) no history of cardiovascular event with encouraging results.

\section{Conclusions and Remarks}

Cardiovascular risk reduction is the novel form to approach the individual cardiovascular risk factors. Several innovative strategies are being implemented with promising results. In Mexico the Mexican Institute of the social security has screening programmes, has developed a preventive model for non-communicable chronic diseases, and it has educational programs to adult risk factors carrier with active participation of the patient, 50/50 program; and is being implemented in children an educational model to modify and reach a healthy lifestyle.

\section{Acknowledgment}

The authors thank the IMSS Foundation its unrestricted support for the preparation and publication of this manuscript. In particular to its General Director, Lic. Patricia Guerra, a visionary woman.

\section{References}

1. Hearth Disease and Stroke Statistics 2018. At-a-Glance. Ref.: https://tinyurl.com/ydbhpbz4

2. Vitalsigns: Preventable Deaths from Heart Disease \& Stroke. CDC. 2013. Ref.: https://tinyurl.com/ybdrhwye

3. Lara A, Rosas M, Pastelín G, Aguilar C, Attie F, et al. Hipercolesterolemia e hipertensión arterial en México. Consolidación urbana actual con obesidad, diabetes y tabaquismo. Arch Cardiol Méx. 2004; 74: 231-245. Ref.: https://tinyurl.com/yb5q9mph

4. Vital signs: Getting Blood Pressure Under Control. CDC. 2012.

5. Rosas-Peralta M, Palomo-Piñón S, Borrayo-Sánchez G, Madrid-Miller A, Almeida-Gutiérrez E, et al Consenso de Hipertensión Arterial Sistémica en México. Rev Med Inst Mex Seguro Soc. 2016; 54 : S6-51. Ref.: https://tinyurl.com/y7klddw9

6. Whelton PK, Carey RM, Aronow WS, Casey DE Jr, Collins KJ, et al. 2017 ACC/AHA/AAPA/ABC/ ACPM/AGS/APhA/ ASH/ASPC/NMA/PCNA Guideline for the Prevention, Detection, Evaluation, 
and Management of High Blood Pressure in Adults: Executive Summary: A Report of the American College of Cardiology/American Heart Association Task Force on Clinical Practice Guidelines. J Am Coll Cardiol. 2017; 71: 1269-1324. Ref.: https://tinyurl.com/y9ne3q62

7. Philippe Gabriel Steg. Evaluation of Cardiovascular Outcomes after an Acute Coronary Syndrome during Treatment with Alirocumab-ODYSSEY OUTCOMES. 2018. Ref.: https://tinyurl.com/y8zxkt44

8. American Diabetes Association. Cardiovascular Disease and Risk Management. Diabetes Care 2015; 38: S49-S57. Ref.: https://tinyurl.com/y7amyz9g

9. CushmanWC, Evans GW, Byington RP. Effects of intensive blood pressure control in type 2 diabetes mellitus. N Engl J Med. 2010; 362: 1575-1585. Ref.: https://tinyurl.com/y7qox7a9

10. Patel A, MacMahon S, Chalmers J, Neal B, Woodward M, et al. Effects of a fixed combination of perindopril and indapamide on macrovascular andmicrovascular outcomes in patients with type 2 diabetesmellitus (the ADVANCE trial): a randomised controlled trial. Lancet. 2007; 370: 829-840. Ref.: https://tinyurl.com/ybdte4qz

11. Hansson L, Zanchetti A, Carruthers SG, Dahlöf B, Elmfeldt D, et al. Effects of intensive bloodpressure lowering and low-dose aspirin in patients with hypertension: principal results of the Hypertension Optimal Treatment (HOT) randomized trial. Lancet. 1998; 351: 1755-1762. Ref.: https://tinyurl.com/ybhpkwbv

12. Wright JT Jr, Williamson JD, Whelton PK, Snyder JK, Sink KM, et al. A randomized trial of intensive versus standard blood-pressure control. N Engl J Med. 2015; 373: 2103-2116. Ref.: https://tinyurl.com/y72m7hyr

13. Rosas-Peralta M, Borrayo-Sanchez G, Ramirez-Arias E, Almeida-Gutierrez E, Garcia-Méndez R, et al. Obesity and Cardiovascular Risk in Mexico: Pathophysiology and Prevention. Obes Control Ther 2017; 4: 1-9. Ref.: https://tinyurl.com/yb5lazzw

14. Encuesta Nacional de Salud y Nutrición de Medio Camino 2016. Ref.: https://tinyurl.com/y8adkuld

15. Knowler WC, Barrett-Connor E, Fowler SE, Hamman RF, Lachin JM, et al. Reduction in the incidence of type 2 diabetes with lifestyle intervention or metformin. N Engl J Med. 2002; 346: 393-403. Ref.: https://tinyurl.com/ybp9jkvx

16. .Wentworth JM, Playfair J, Laurie C, Ritchie ME, Brown WA, et al. Multidisciplinary diabetes care with and without bariatric surgery in overweight people: a randomised controlled trial. Lancet Diabetes Endocrinol. 2014; 2: 545-552. Ref.: https://tinyurl.com/y7cwbwrq

17. Adams TD, Arterburn DE, Nathan DM, Eckel RH. Clinical outcomes of metabolic surgery: microvascular and macrovascular complications. Diabetes Care. 2016; 39: 912-923. Ref.: https://tinyurl.com/y8z8sjv3

18. Sjöström L, Narbro K, Sjöström CD, Karason K, Larsson B, et al. Effects of bariatric surgery on mortality in Swedish obese subjects. N Engl J Med. 2007; 357: 741-752. Ref.: https://tinyurl.com/yc8lcuxx

19. Guasch-Ferré M, Salas-Salvadó J, Ros E, Estruch R, Corella D, et al. The PREDIMED Investigators. The PREDIMED trial, Mediterranean diet and health outcomes: How strong is the evidence? Nutr Metab Cardiovasc Dis. 2017; 27: 624-632. Ref.: https://tinyurl.com/y7rowpxx

20. IMSS. MODELO PREVENTIVO DE ENFERMEDADES CRÓNICAS. Ref.: https://tinyurl.com/yc29ehxh

21. Fuster V. Ref.: https://tinyurl.com/ybq5wqmp

22. Peñalvo JL, Santos-Beneit G, Sotos-Prieto $M$, Bodega $P$, Oliva B, et al. The SI! Program for Cardiovascular Health Promotion in Early Childhood A Cluster-Randomized Trial. J Am Coll Cardiol. 2015; 66: 1525-1534. Ref.: https://tinyurl.com/ya88jmqm 